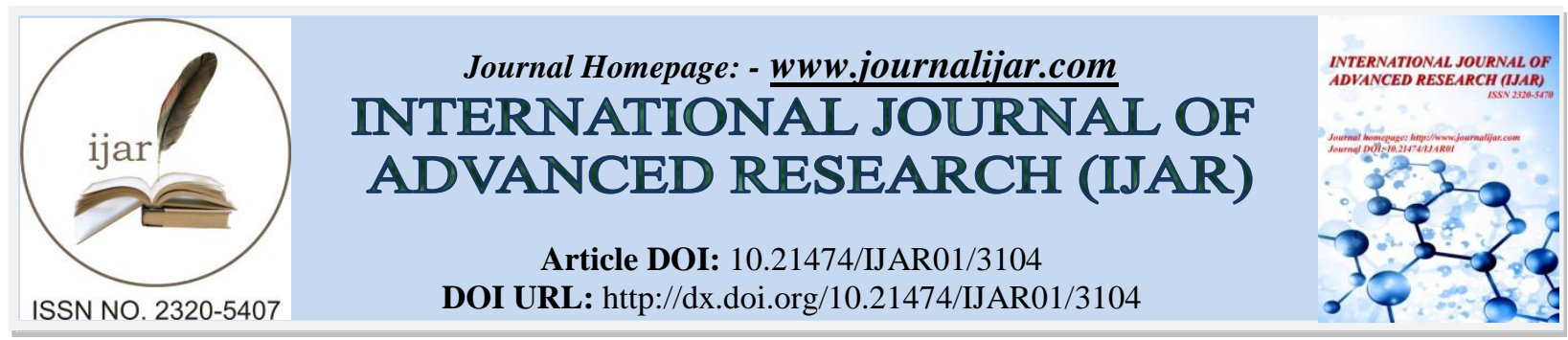

RESEARCH ARTICLE

\title{
METFORMIN AND ITS SIDE EFFECTS.
}

\section{Sulaiman Saleh Alaqil ${ }^{1}$, Moneef Mansour Aldosari ${ }^{2}$, Abdulelah Sulaiman Almaiman ${ }^{3}$, Hesham Abdullah} Almuaili $^{4}$ and Khwlah Mohammed Alreshaid ${ }^{5}$.

1. King Abdullah st., Riyadh City, Kingdom of Saudi Arabia, Al Imam Muhammed bin Saud Islamic University, College of Medicine, Student.

2. Alwaseet St., Riyadh City, KSA Al Imam Muhammed bin Saud Islamic University, College of Medicine, Student.

3. King Fahad St., Riyadh City, KSA, Imam University, College of Medicine, Internship.

4. Prince Muteb St., Riyadh City, KSA, Imam University, College of Medicine, student.

5. King fahad St., Riyadh City, KSA, Nephrology service resident, King Saud Medical City.

\section{Manuscript Info}

Manuscript History

Received: 1 December 2016

Final Accepted: 30 December 2016

Published: January 2017

Key words:-

Metformin, DM, Side effects

\section{Abstract}

Metformin and its Side Effects:- Objective: This research aims at investigating the effects of using metformin among Saudi patients in Riyadh.

Methodology: (67) males and (57) females have been selected randomly to participate in this research. Self-reported questionnaire has been given to participants. Continuous variables were expressed as mean \pm standard deviation and categorical variables were expressed as percentages. The t-test was used for continuous variables and chi square test was used for categorical variables. A p-value $<0.05$ was considered statistically significant.

Results: many patients reported diarrhea and nausea as the main side effects of using this medication. However, $50 \%$ of participants have no complain. This project found no significant difference between two genders except age \&using metformin.

Conclusion: metformin has been used widely among Saudi patients suffering from type 2 DM. Many patients complain from side effect of this medication.

\section{Introduction:-}

Metformin, or otherwise known as Glucophage, is an oral first-line medication to treat Type-2 diabetes. Type 2 Diabetes or Diabetes mellitus type 2 is a condition where a relative lack of insulin, along with insulin resistance and high blood pressure is observed. Metformin, along with this chronic long-term diabetes, can also be used to treat polycystic ovary syndrome, common amongst the overweight young women.

In type 2 diabetes cases, Metformin increases insulin sensitivity and improves glycaemic control in the patient. The glucose production decreases in the liver so that insulin could work efficiently (1). Coupled with this, Metformin is also said to prevent cardiovascular diseases and cancer complications in a diabetic patient (2). This has also been stated by many studies where the use of Metformin may have lowered cancer risks far greater than other anti- 
diabetic drugs (3). In addition to that, in several clinical trials, antitumoral effects have been observed, especially in colon region and breasts (4). If taken with diet and exercise, Metformin works remarkably. It is repeatedly prescribed to the patients not to chewor crush the tablet. Instead, it is preferred to be swallowed as a whole.

Keeping its amazing benefits on one side, Metformin is said to cause some serious side effects as well. The common ones include nausea, vomiting, upset stomach with abdominal pains, or diarrhoea which are mostly characterized as gastrointestinal effects and will be discussed later on in Literature Review. Severe headaches and skin rashes are also very common. Apart from this, Metformin also rarely causes lactic acidosis, which is the excess building up of lactic acid in the body and can be fatal. This will also be elaborated in the literature review.

\section{Literature Review:-}

Metformin should be avoided in cases when the patient experiences any sort of allergic reactions. For instance, hives, or difficulty in breathing, swelling up of facial organs such as tongue, lip or the entire face, or even throat swelling (5). These are the indications that Metformin dosage or the entire medication prescription needs to be consulted again with the doctor because of inadequate response of the patient towards the medicine.

Gastrointestinal effects of Metformin have repeatedly been studied and reviewed by physicians and scholars, and all of them state that these results, if not treated on time, can be fatal as well depends on the drug dosage. In a clinical trial, consisting of 286 subjects, all given Metformin, 141 or $53.2 \%$ of the respondents gave reports of diarrhoea while $25.5 \%$ of them said that they felt nauseous and even vomited (6). Gastrointestinal issues can cause serious discomfort, if not treated earlier. Most commonly, it is prominent when the dosage is increased or when Metformin is initially administered. To avoid this, either the dose should be decreased or if it's necessary to consume a larger dose, then it should be increased gradually so the body can get used to the daily consumption.

The most serious side effects of Metformin include Lactic Acidosis. It is also referred to as "metformin-associated lactic acidosis," or MALA. The few symptoms of Lactic Acidosis include severe drowsiness, muscle pain, tiredness, fast or difficult breathing, along with gastrointestinal symptoms as stated earlier, child or cold/blue skin, and others similar to these (7). Even though MALA is approximately 9 per 100,000 person-years (8), it can be fatal in many cases. A similar drug, called Phenformin, was called off from the market because of its high rates of causing lactic acidosis, around 40-64 per 100,000 patient-years (9). Metformin is relatively safer than Phenformin, and the risk of developing lactic acidosis is restricted to specific high-risk groups (9).

Along with all this, Metformin is also said to increase lactic acid production in the large intestine (10). Increased lactic acidosis is mostly common in the patients suffering from heart diseases, kidney issues, or even respiratory diseases (11).

Metformin does not usually cause hyperglycemia, but if it is used with other anti-diabetic drugs, low blood sugar can prevail. Coupled with this, if the patient is exercising too much, or not consuming enough energetic calories from his meals, or even drinking large amounts of alcohol, Metformin may lead to extremely lower levels of blood sugar, which is very dangerous for the patient.

The side effects of Metformin are usually more evident in older people, mostly above the age of 80 years. At that age, heart failures, strokes, liver or kidney diseases are more prevalent, and the doctor needs to be informed of them before Metformin is prescribed to the patient (12). Several studies, taking place in Texas between 2000 and 2006, stated the fact that ingest doses of $5000 \mathrm{mg}$ caused more drastic effects in adults (13). Several other studies and data revealed the fact of some intentional overdose cases, resulting in the survival of the patient. The dose was as high as 63,000 mg, i.e. 63 grams of Metformin (14).This comparison shows that Metformin's side effects do not depend on it'soverdosage. It majorly negatively harms the adult than the younger ones.

Metformin is said to be contraindicated in those people who have the diseases mentioned above, such as heart failures, kidney or liver diseases (defined as creatinine levels over $150 \mu \mathrm{mol} / \mathrm{l}(1.7 \mathrm{mg} / \mathrm{dl}$ ), or any respiratory or lung diseases (15). These may cause the patient to develop lactic acidosis at a much higher rate than otherwise. This has also been reinstated by several studies which link the high occurrence of lactic acidosis to the patient's infection of heart disease and his/her consuming of Metformin (16). 
Table 2:- Comparison of using metformin by age group.

\begin{tabular}{|c|c|c|c|c|c|c|c|}
\hline & \multirow{2}{*}{\multicolumn{2}{|c|}{$\begin{array}{c}\text { Age }<45 \text { years } \\
20\end{array}$}} & \multicolumn{2}{|c|}{ Age 45-65years } & \multicolumn{2}{|c|}{ Age $>65$ years } & \multirow[t]{3}{*}{$\mathrm{P}$ value } \\
\hline & & & & 76 & & 28 & \\
\hline & \multicolumn{2}{|r|}{$\mathrm{n}(\%)$} & \multicolumn{2}{|r|}{$\mathrm{n}(\%)$} & \multicolumn{2}{|r|}{$\mathrm{n}(\%)$} & \\
\hline \multicolumn{8}{|l|}{ Gender } \\
\hline Male & 3 & $(15.00 \%)$ & 42 & $(55.26 \%)$ & 22 & $(78.57 \%)$ & \multirow[t]{2}{*}{$<0.001 *$} \\
\hline Female & 17 & $(85.00 \%)$ & 34 & $(44.74 \%)$ & 6 & $(21.43 \%)$ & \\
\hline Dose & \multicolumn{2}{|c|}{$500 \pm 0.00$} & \multicolumn{2}{|c|}{$500 \pm 0.00$} & \multicolumn{2}{|c|}{$500 \pm 0.00$} & \\
\hline \multicolumn{8}{|l|}{ Using metphormin } \\
\hline for DM & 4 & $(20.00 \%)$ & 52 & $68.42 \%$ & 25 & $(89.29 \%)$ & \multirow[t]{4}{*}{$<0.001 *$} \\
\hline for obesity & 0 & $(0.00 \%)$ & 2 & $2.63 \%$ & 0 & $(0.00 \%)$ & \\
\hline PCOS & 16 & $(80.00 \%)$ & 1 & $1.32 \%$ & 0 & $(0.00 \%)$ & \\
\hline DM\& Obesity & 0 & $(0.00 \%)$ & 21 & $27.63 \%$ & 3 & $(10.71 \%)$ & \\
\hline Other medications & 3 & $(15.00 \%)$ & 32 & $(42.10 \%)$ & 25 & $(89.29 \%)$ & $<0.001 *$ \\
\hline \multicolumn{8}{|l|}{ Side effect of Metformin use } \\
\hline Nausea & 0 & $(0.00 \%)$ & 5 & $(6.58 \%)$ & 3 & $(10.71 \%)$ & \multirow[t]{12}{*}{$0.049 *$} \\
\hline Gases & 0 & $(0.00 \%)$ & 2 & $(2.63 \%)$ & 0 & $(0.00 \%)$ & \\
\hline Diarrhea & 4 & $(20.00 \%)$ & 15 & $(19.74 \%)$ & 3 & $(10.71 \%)$ & \\
\hline Headache & 1 & $(5.00 \%)$ & 1 & $(1.32 \%)$ & 0 & $(0.00 \%)$ & \\
\hline Nausea\& Vomiting & 0 & $(0.00 \%)$ & 1 & $(1.32 \%)$ & 0 & $(0.00 \%)$ & \\
\hline Nausea\& Diarrhea & 1 & $(5.00 \%)$ & 4 & $(5.26 \%)$ & 6 & $(21.43 \%)$ & \\
\hline Gases\& Diarrhea & 1 & $(5.00 \%)$ & 5 & $(6.58 \%)$ & 3 & $(10.71 \%)$ & \\
\hline Gases\& Headache & 0 & $(0.00 \%)$ & 1 & $(1.32 \%)$ & 0 & $(0.00 \%)$ & \\
\hline Diarrhea\& Headache & 2 & $(10.00 \%)$ & 0 & $(0.00 \%)$ & 1 & $(3.57 \%)$ & \\
\hline Nausea\& Vomiting\& Gases & 0 & $(0.00 \%)$ & 0 & $(0.00 \%)$ & 1 & $(3.57 \%)$ & \\
\hline Nausea\& Vomiting \&Diarrhea & 0 & $(0.00 \%)$ & 0 & $(0.00 \%)$ & 2 & $(7.14 \%)$ & \\
\hline Nothing & 11 & $(55.00 \%)$ & 42 & $(55.26 \%)$ & 9 & $(32.14 \%)$ & \\
\hline \multicolumn{7}{|l|}{ Duration of symptoms } & \multirow[t]{7}{*}{0.112} \\
\hline 1 day & 12 & $(60.00 \%)$ & 13 & $(17.11 \%)$ & 0 & $(0.00 \%)$ & \\
\hline 1 week & 0 & $(0.00 \%)$ & 11 & $(14.47 \%)$ & 3 & $(10.71 \%)$ & \\
\hline 1 month & 5 & $(25.00 \%)$ & 22 & $(28.95 \%)$ & 7 & $(25.00 \%)$ & \\
\hline$<=6$ month & 3 & $(15.00 \%)$ & 6 & $(7.89 \%)$ & 1 & $(3.57 \%)$ & \\
\hline$<=1$ year & 0 & $(0.00 \%)$ & 13 & $(17.11 \%)$ & 12 & $(42.86 \%)$ & \\
\hline$<=3$ year & 0 & $(0.00 \%)$ & 11 & $(14.47 \%)$ & 5 & $(17.86 \%)$ & \\
\hline \multicolumn{8}{|l|}{ Start feeling symptoms } \\
\hline During the $1^{\text {st }}$ hour after taking the medicine & 7 & $(35.00 \%)$ & 17 & $(22.37 \%)$ & 3 & $(10.71 \%)$ & \multirow[t]{2}{*}{0.619} \\
\hline After the $1^{\text {st }}$ hour & 13 & $(65.00 \%)$ & 59 & $(77.63 \%)$ & 25 & $(89.29 \%)$ & \\
\hline \multicolumn{8}{|l|}{ Time of taking medicine } \\
\hline Before eating & 3 & $(15.00 \%)$ & 7 & $(9.21 \%)$ & 4 & $(14.29 \%)$ & \multirow[t]{3}{*}{0.218} \\
\hline During eating & 3 & $(15.00 \%)$ & 4 & $(5.26 \%)$ & 0 & $(0.00 \%)$ & \\
\hline After eating & 14 & $(70.00 \%)$ & 65 & $(85.53 \%)$ & 24 & $(85.71 \%)$ & \\
\hline Inform the physician about the symptoms & 18 & $(90.00 \%)$ & 47 & $(61.84 \%)$ & 24 & $(85.71 \%)$ & 0.125 \\
\hline Using medicines to relieve such symptoms & 6 & $(30.00 \%)$ & 16 & $(21.05 \%)$ & 7 & $(25.00 \%)$ & 0.589 \\
\hline
\end{tabular}


Figure 1:-

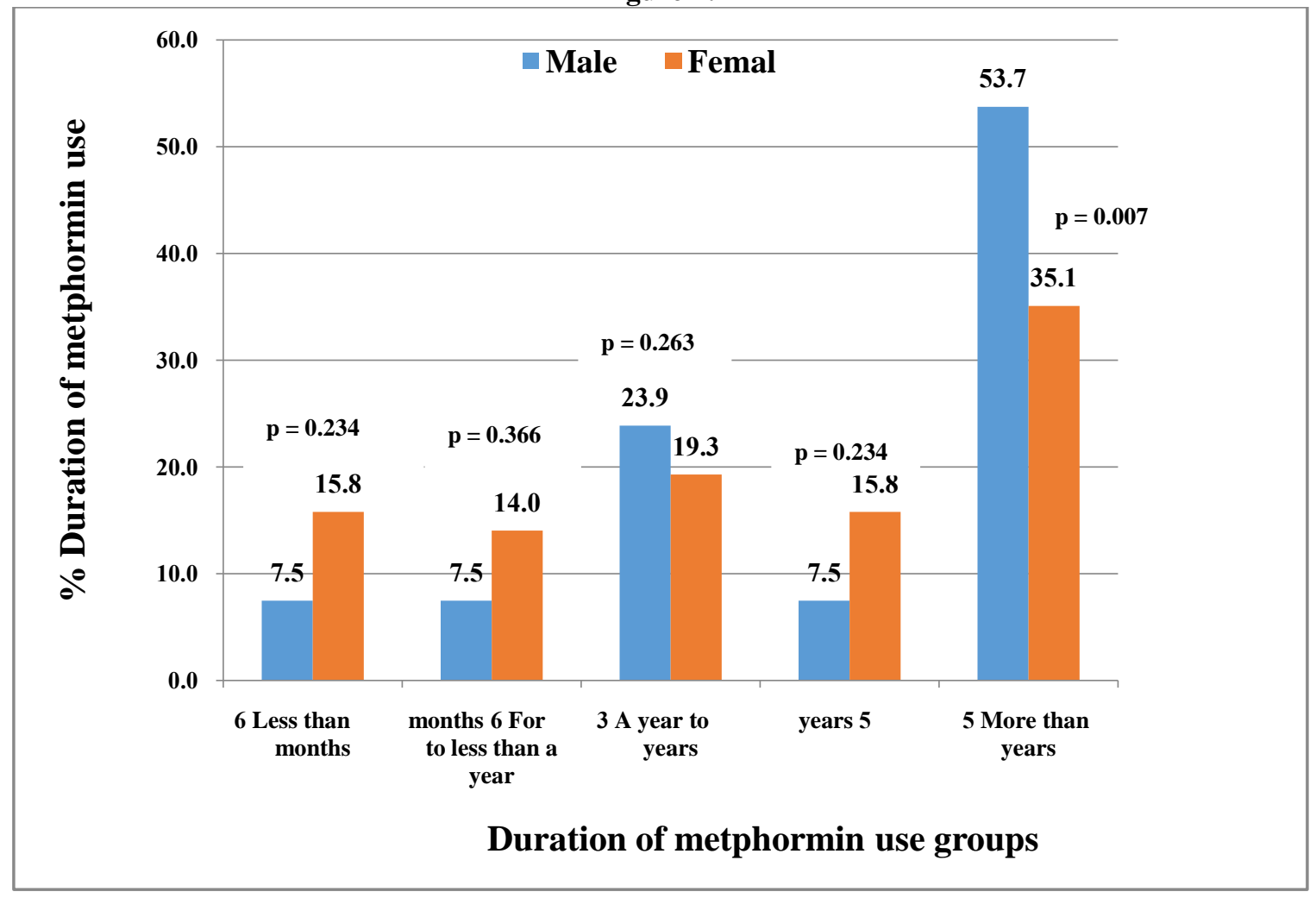

Duration of metformin use for two genders. The data are presented by percentage (\%). P-value had been calculated between two genders. Duration of metformin use for female gender was significantly lower in duration group more than 5 years when compared with all other duration groups.

\section{Discussion:-}

Metformin is used as a prescription to type 2 Diabetes mellitus. This project investigated the harms resulting in the use of such medication among Saudi patients. Many patients reported diarrhea and nausea as the main side effects of metformin. However, half of participants don't get the same suffering. This project found no significant difference between two genders except age \&using metformin.

Similar findings have been reported in other publications. In a clinical trial, consisting of 286 subjects, all given Metformin, 141 or $53.2 \%$ of the respondents gave reports of diarrhoea while $25.5 \%$ of them said that they felt nauseous and even vomited (Drug Facts and Comparisons, 2005). Gastrointestinal issues can cause serious discomfort, if not treated earlier. Most commonly, it is prominent when the dosage is increased or when Metformin is initially administered.

In conclusion, metformin is widely used among diabetic Saudi patients. Side effects as result of using this medication should be expected. Heath education can help to reduce the severity of these complains.

Qualitative study should be launched to give in details explanations regarding the side effect of the use of metformin among diabetic patients in all age groups.

\section{Acknowledgments:-}

Authors would like to express their sincere gratitude to Dr. Nasser Alkahtani for the continuous support he provided to them throughout preparing the manuscript. 


\section{References:-}

1. Kirpichnikov D, McFarlane SI and Sowers JR. (2002) 'American college of physicians,' Annals of Internal Medicine. 137(1):25-33.

2. Drugs.com. (2016)."Metformin hydrochloride". Available from https://www.drugs.com/monograph/metforminhydrochloride.html .

3. Evans JMM, Donnelly LA, Emslie-Smith AM, Alessi DR and Morris AD (2005) 'Metformin and reduced risk of cancer in diabetic patients' $B M J$. 330:7503.

4. Chong C andChabner B. (2009) 'Mysterious metformin', The oncologist. 14(12):1178-81.

5. Drugs.com (2000). "Metformin: Uses, dosage, side effects". Available from: https://www.drugs.com/metformin.html.

6. Drug.com. (2005). "Facts and Comparisons". Available from https://www.drugs.com/ppa/

7. Scheen AJ, Paquot N. (2013) "Metformin revisited: a critical review of the benefit-risk balance in at-risk patients with type 2 diabetes". Diabetes Metab. 39(3):179-90.

8. Stang M, Wysowski DK and Butler-Jones D. (1999) "Incidence of lactic acidosis in metformin users", Diabetes Care. 22(6): 925-927.

9. Salpeter SR, Greyber E, Pasternak GA and Salpeter EE. (2003) "Risk of Fatal and Nonfatal Lactic Acidosis with Metformin use in type 2 diabetes Mellitus" Archives of Internal Medicine. 163(21):2594-2602. doi: 10.1001/archinte.163.21.2594.

10. Kirpichnikov D, McFarlane S and Sowers J. (2002) 'Metformin: An update' Annals of internal medicine.137(1):25-33.

11. Williams L and Wilkins: "Pathophysiology", A Wolters Kluwer Company, Philadelphia, 2005.

12. MedlinePlus.(2016). Metformin. Available from https://medlineplus.gov/druginfo/meds/a696005.html

13. Forrester M. (2008) "Adult metformin ingestions reported to Texas poison control centers, 2000-2006", Hum ExpToxicol. 27(7):575-583. doi: 10.1177/0960327108090589.

14. Gjedde S, Christiansen A, Pedersen SB and Rungby J. (2003) "Survival following a Metformin overdose of 63 g: A case report", Pharmacology \& Toxicology. 93(2):98-99. doi: 10.1034/j.1600-0773.2003.930207.x.

15. Jones GC, Macklin JP and Alexander WD. (2003) "Contraindications to the use of metformin", Editorial. 326(7379):4-5. doi: 10.1136/bmj.326.7379.4.

16. Bristol-Myers Squibb Company. (no date). "GLUCOPHAGE®" Available at: http://www.accessdata.fda.gov/drugsatfda_docs/label/2008/020357s031,021202s016lbl.pdf $\quad$ (Accessed: 11 November 2016). 